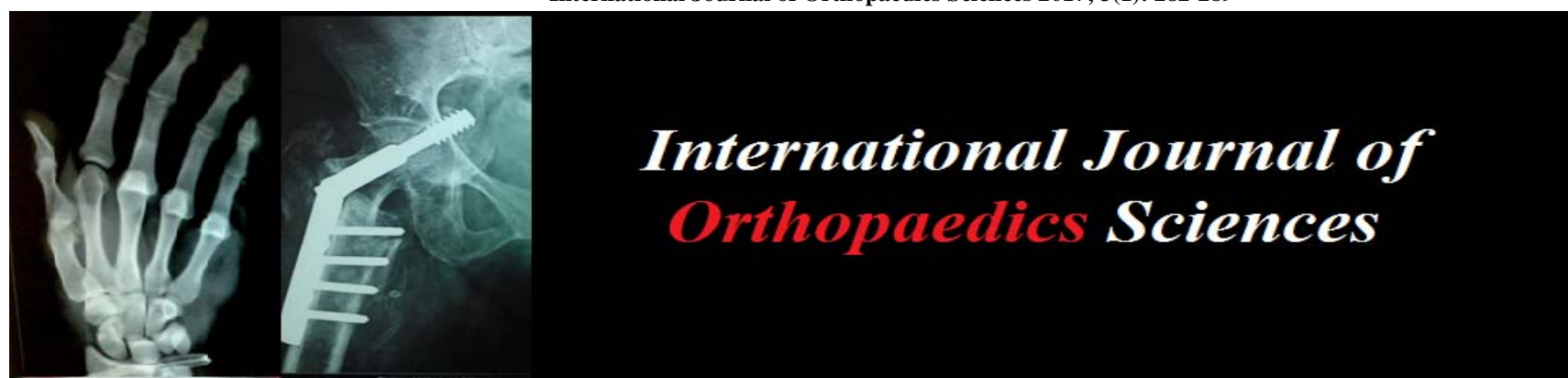

ISSN: $2395-1958$

IJOS 2017; 3(1): 282-289

(C) 2017 IJOS

www.orthopaper.com

Received: 15-11-2016

Accepted: 16-12-2016

Dr. C V Mudgal

Associate Professor,

Orthopaedics department

Karnataka Institute of Medical

Sciences, Hubli, Karnataka,

India

Dr. Viresh Murgodi

Assistant Professor,

Orthopaedics Department,

Shridevi Institute of Medical

Sciences and Research Hospital,

Tumkur, Karnataka, India
Correspondence

Dr. CV Mudgal

Associate Professor,

Orthopaedics department

Karnataka Institute of Medical

Sciences, Hubli, Karnataka,

India

\section{Surgical management of unstable supracondylar fractures of humerus in children by closed reduction and percutaneous $k$ wire fixation by crossed versus triple pin configuration: A comparative study}

\section{Dr. CV Mudgal and Dr. Viresh Murgodi}

DOI: http://dx.doi.org/10.22271/ortho.2017.v3.i1e.45

\section{Abstract}

Background: Supracondylar fracture of humerus in children is one of the most common fractures seen in pediatric orthopedic clinic setting worldwide. Closed reduction and percutaneous $\mathrm{K}$ wire fixation is preferred method of treatment and should be attempted at earliest possible time. In this study, displaced extension type supracondylar fractures in children were managed with closed reduction and percutaneous $\mathrm{K}$ wire fixation using image intensifier so as to study age, sex incidence and side preponderance, assess clinical and radiological outcomes. To compare clinical outcomes in two types of pin configurations (crossed and triple) and early and late complications associated with these procedures.

Materials and methods: This study was conducted between June 2013 and June 2015 in the Department of Orthopaedics in Karnataka Institute of Medical Sciences, Hubballi. The mean age of the patients was 8.73 years (range 6-13 years). The male/female ratio was 3:1 and left side was involved in $53.8 \%$ whereas $42.2 \%$ had right sided injuries. All the 26 admitted patients had extension type injury with $96.15 \%$ fractures being Gartland type III and $3.85 \%$ were type II. Posteromedial displacement was noted in $57.7 \%$ whereas $42.3 \%$ fractures were posterolaterally displaced. In 13 cases, crossed $\mathrm{K}$ wires were used whereas, in 13 cases, two lateral and one medial K-wire was used. K-wires were removed at 4 weeks postoperatively and follow-up was done at 8,12 weeks and final follow-up at 6 months when they were evaluated according to the criteria described by Flynn. Chi-square test and Fischer -Exact test was used as a statistical tools to compare results among different variables.

Results: All 26 patients had satisfactory outcomes $(100 \%)$ as per Flynn's criteria. Although Triple pinning has shown better results but there was no statistical difference in the final outcomes and complication rates in patients treated by either crossed or triple pinning technique due to small sample size. Younger age patients were found to have better final clinical outcomes to older children. Patients who had Baumann angle within 4 degrees compared to normal side had better final outcomes and it can used as a reliable radiologic parameter to assess adequacy of reduction.

Conclusion: Closed reduction and percutaneous fixation using $\mathrm{K}$ wires gives excellent results and is the most accepted modality for treating displaced supracondylar fractures of humerus in children. Triple pinning has shown encouraging results in comparison to Crossed pinning, but larger sample size is needed to give statistical significance to the comparative study.

Keywords: Percutaneous pinning, supracondylar fracture humerus, triple pinning, crossed pinning

\section{Introduction}

Supracondylar fracture of humerus in children is one of the most common fractures seen in paediatric orthopaedic clinic setting worldwide. It accounts for $65.4 \%$ of upper extremity fractures in 5-10 year age group in children ${ }^{[1]}$. Various methods have been used for management of displaced fractures like closed reduction and cast application, skin traction, overhead skeletal traction, closed reduction or open reduction and percutaneous $\mathrm{K}$ wire fixation ${ }^{[2]}$.

Closed reduction and percutaneous pinning under fluoroscopic guidance is the procedure of choice for the treatment of these fractures whenever possible and the original Swenson technique of cross pinning continues to be used today with excellent results and low morbidity. In the developing world, proportion of delayed presentation is much higher because of poorly developed health delivery system and patients reaching the tertiary care centers from long distance ${ }^{[3]}$. The goal of treatment in children is to achieve and maintain a close to anatomic 
Reduction until the fracture is proper healed, whereas minimizing the risks of complications. Closed reduction and percutaneous pinning have become a standard method of treatment although controversy persists concerning the optimal pin configuration ${ }^{[4]}$

The purpose of this study is to evaluate the age, sex and side incidence, radiological and functional outcome in closed reduction and percutaneous $\mathrm{K}$ wire fixation and comparative study of clinical outcomes, post-operative complications in crossed and triple pinning.

\section{Materials and methods}

Twenty Six displaced, closed extension type of supracondylar fractures (Gartland's type II and III) of humerus in children were treated by closed reduction and internal fixation by percutaneous K wires between July 2013 and October 2015. Two pin configurations crossed pinning (referred to as group C) and Triple pinning (referred to as Group $T$ ) for percutaneous $\mathrm{K}$ wire fixation were done and the functional and radiological outcomes among the two treatment groups were compared. This study was conducted in Karnataka Institute of Medical Sciences, Hubballi. Permission was taken from Ethical committee prior to start of the study.

Age less than 13 years, patients presenting and operated within 72 hours of the injury, Gartland's type II and III fractures(Unstable fractures) were included. Open fractures and patients presenting with neurovascular complications, patients presenting after $72 \mathrm{hrs}$ of injury and patients with associated fractures around the elbow and ipsilateral upper limb fractures were excluded. Plain radiograph of elbow in A$\mathrm{P}$ and Lateral views affected and normal side were taken. Based on the radiographs all cases were classified according to Gartland's classification ${ }^{5}$ and Type II and III were selected. Type II fractures were managed by selective pinning i.e the fractures where satisfactory reduction was not obtained or after 5-6 days post reduction radiograph showed loss of reduction were managed by pinning. Routine laboratory investigations like complete blood counts, RBS, Renal function tests and $\mathrm{HIV}$ and HBsAg and Chest $\mathrm{X}$ ray PA view were done and immediately taken up for surgery. One dose of Inj ceftriaxone as per body weight was given $30 \mathrm{~min}$ before start of procedure.

2.1 Operative technique- Patients were given general anesthesia and placed supine on the operating table, with the $\mathrm{C}$-arm screen used as an operating table. Closed reduction was performed under image intensification. Initially sustained longitudinal traction was given with elbow in extension and forearm in supination and counter traction applied by assistant. This manoeuvre corrected the impaction. Next the mediolateral displacement was corrected by valgus or varus force at fracture site. The posterior displacement of the distal fragment was corrected next by applying a anterior force over olecranon process with gradual flexion of elbow and pronation of forearm, triceps muscle acts as an internal splint.

Anatomic reduction (Baumann angle within 4 degree of normal side) is confirmed with the image intensifier before pinning. If reduction is satisfactory, parts are painted and draped. The lateral pin is always inserted first. The insertion site is made at an angle of 30 degree so that the pin will traverse the lateral portion of the ossified capitellum, cross the physis, proceed up the lateral column, and always engage the opposite medial cortex proximally. Using a Kirschner wire (1.5 or $1.8 \mathrm{~mm}$ ), the position for inserting the pin is documented on AP and lateral views. A small incision is made in the skin. The pin is placed using a power drill and a sharp
K-wire. Provisional stability is achieved with the first pin. In case triple pinning a lateral pin is inserted, then the second lateral pin is inserted next in divergent manner followed by medial pin with elbow in extension to avoid ulnar nerve.

In case of crossed pinning, a lateral pin is drilled and then second pin is placed medially. The position of the K-wire from the medial side is confirmed with fluoroscopy. The medial pin is generally more horizontal than the lateral pin and should traverse the medial column and engage the opposite lateral cortex ${ }^{[6]}$.

Pins were bent to prevent pin migration and $1 \mathrm{~cm}$ length was left behind for removal after 4 weeks without need of anesthesia. Post-operative radiographs of elbow-AP and lateral views were taken. Post-operatively all patients were given well-padded high above elbow POP slab with 90 degree elbow flexion and strict limb elevation. Patient was encouraged to do active finger movements. Appropriate antibiotics and analgesics were initiated and regular monitoring of neurovascular status was done. Patients were discharged after 4-5 days in absence of any complications. At 4 weeks follow up, check $\mathrm{x}$ ray was done and $\mathrm{K}$ wire were removed and active range of motion exercises were initiated. Patient relatives were advised not to massage or passively stretch elbow joint as it may lead to myositis ossificans. Patient was advised regular follow up at 4, 8 weeks and final follow up at 6 months. At final follow up patient was examined clinically for loss of flexion and extension and cosmetically by loss of carrying angle. Radiological parameters like Baumann's angle, ulnohumeral angle were noted. The results were graded as excellent, good, fair and poor using Flynn's criteria ${ }^{[1]}$.

\section{Results}

Age distribution was 6- 13 yrs. Most of the patients were in 610 yrs group (88.5\%). Both the study groups are similar in terms of age $(\mathrm{P}$ value $=0.180)$. Mean age of patients was $8.31 \pm 1.84$ yrs. Out of 23 patients in 6-10 yrs of age, 16 patients showed excellent results and 7 had good results. In 1115 yrs age group, 2 had good results and 1 had fair result as per Flynn criteria. Moderate significance could be given to younger patients having better final outcomes than older children ( $\mathrm{P}=0.014$, significant, Fisher Exact test). Overall $76.9 \%$ were males compared to $23.1 \%$ females. Of the total 26 patients, 14 patients had fracture on left side $(53.8 \%)$ and 12 patients on right side $(46.2 \%)$. Out of total 26 patients, 1 patient $(3.8 \%)$ had type 2 fracture, 15 patients $(57.7 \%)$ had type $3 \mathrm{~A}$ and 10 patients $(38.5 \%)$ had type $3 \mathrm{~B}$. In our study mean injury to surgery time delay was 2.46 days. $7.7 \%$ patients were operated within 1 day, $38.5 \%$ patients within 2 days and $53.8 \%$ within 3 days Mean time for union was 7 weeks and all patients signs of union at 4 weeks follow-up.

21 Patients had loss of Baumann angle within 5 degree compared to normal side $(n=21)$, among them $14(66.66 \%)$ patients showed excellent and $7(33.3 \%)$ showed good outcomes. In comparison if loss of Baumann angle is more than 5 degree, then excellent outcome was seen in only $40 \%$ patients and $40 \%$ showed good outcome and $10 \%$ showed fair outcome showing positive association between maintenance of Baumann angle and final clinical outcome. $(\mathrm{P}=0.141$, positive association, Fisher Exact test).

In our study, 16 patients $(61.5 \%)$ had excellent, 9 patients (34.6\%) and 1 patient $(3.8 \%)$ had fair outcome as per Flynn criteria. None of the patient had poor outcome. Statistically no significance could be attached to the difference in the final outcome between the two study groups. $(\mathrm{P}=0.688$, Not significant, Fisher Exact test) 
19 out of total 26 patients did not have post-operative complications.4 patients (15.4\%) had superficial pin tract infection. 2 patients $(7.7 \%)$ had pin migration during postoperative period. 1 patient had post-operative varus deformity. No case of iatrogenic nerve injury was noted. Complication rates were similar between the two groups $(\mathrm{P}=0.378$, Not significant, Fisher Exact test)

Case 1: Crossed pinning group
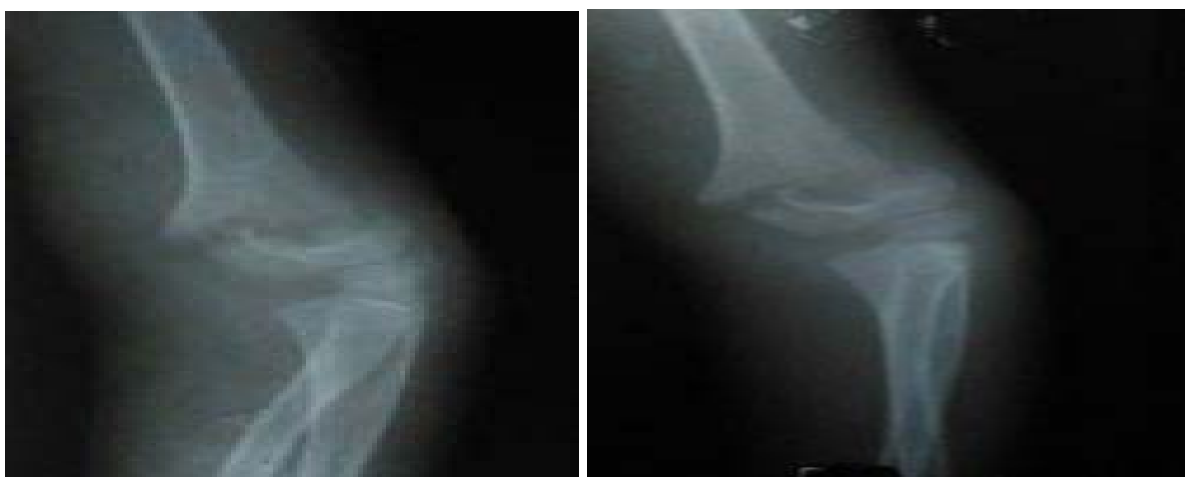

Fig 1: Pre-operative radiograph showing type III Gartland's supracondylar fracture
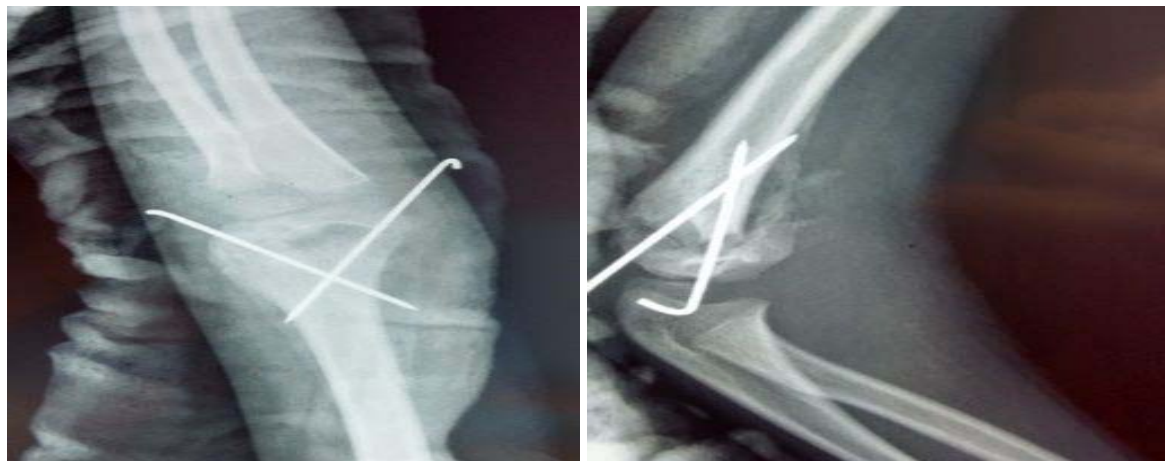

Fig 2: Immediate post-operative radiograph with two $\mathrm{K}$ wires insitu, 1 medial and 1 lateral
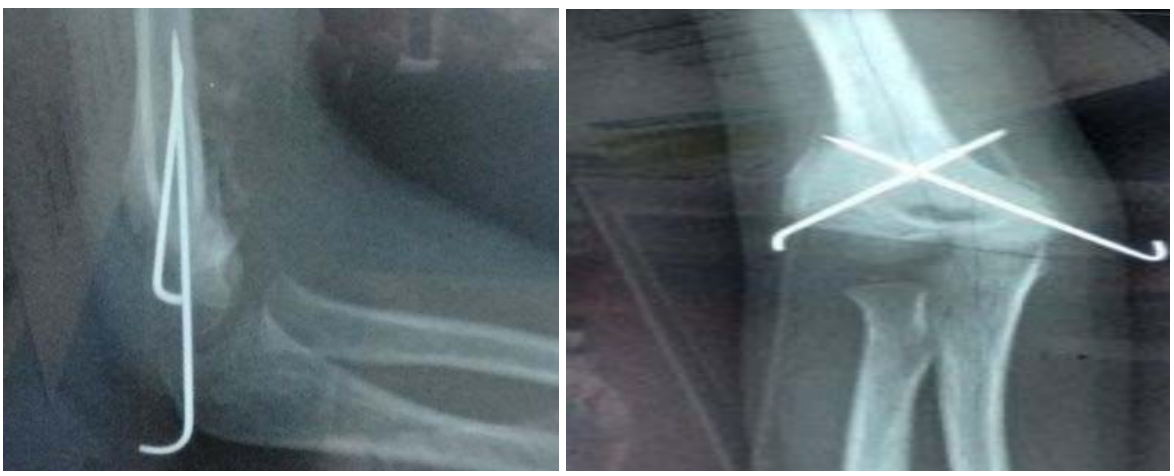

Fig 3: Radiograph at 4 weeks showing callous formation.
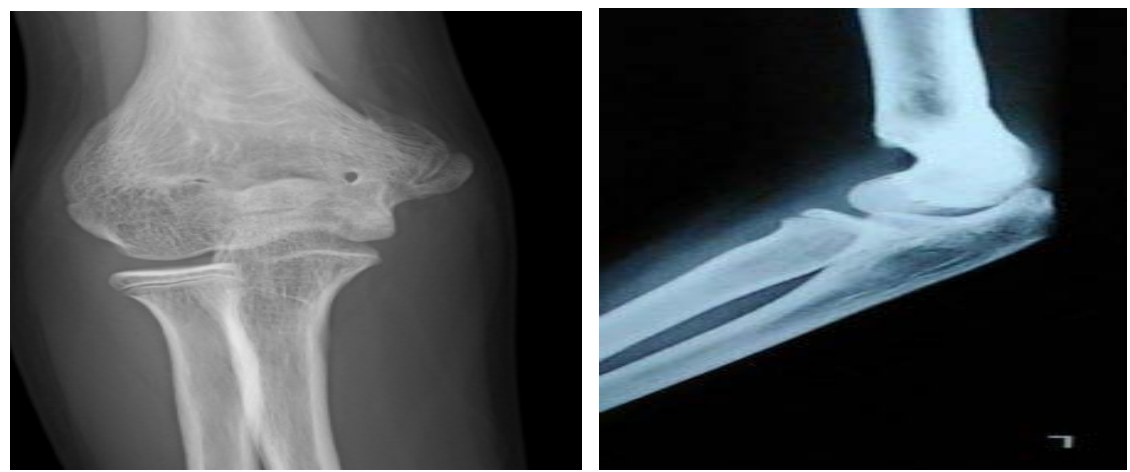

Fig 4: Radiograph at 6 months follow-up 

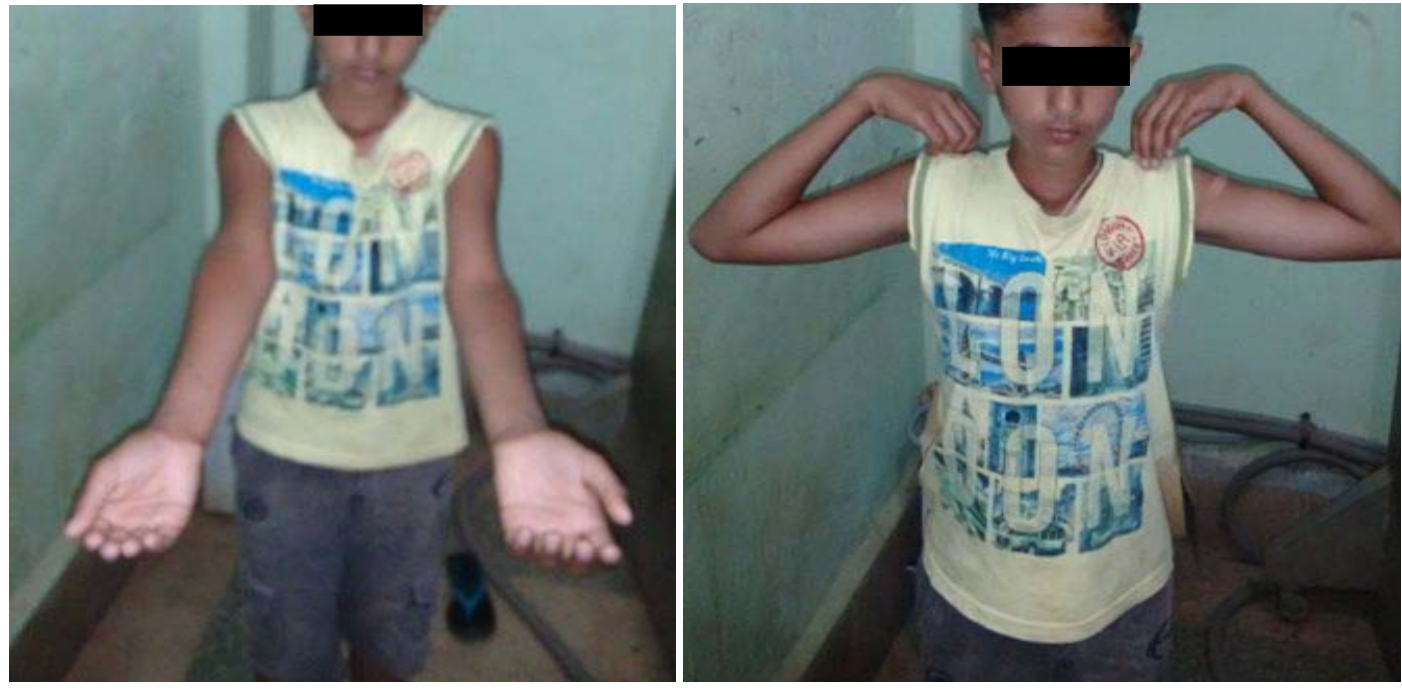

Fig 5: Clinical photograph at 6 months-Flexion and Extension

Case 2: Triple pinning group
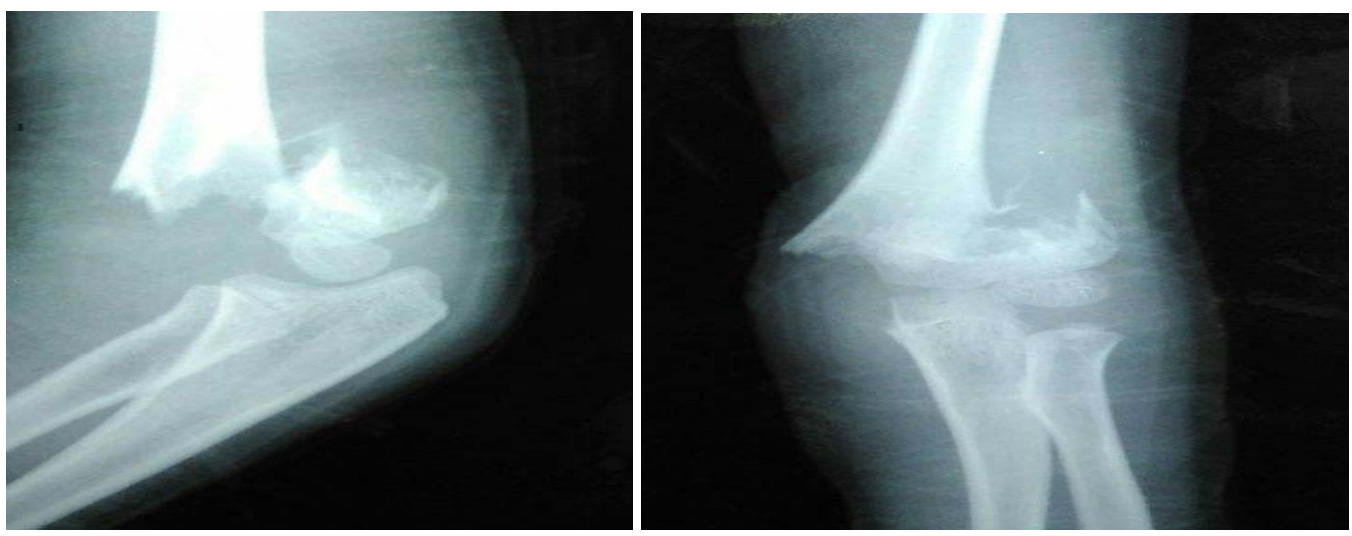

Fig 6: Pre-operative radiograph showing type III Gartland supracondylar fracture
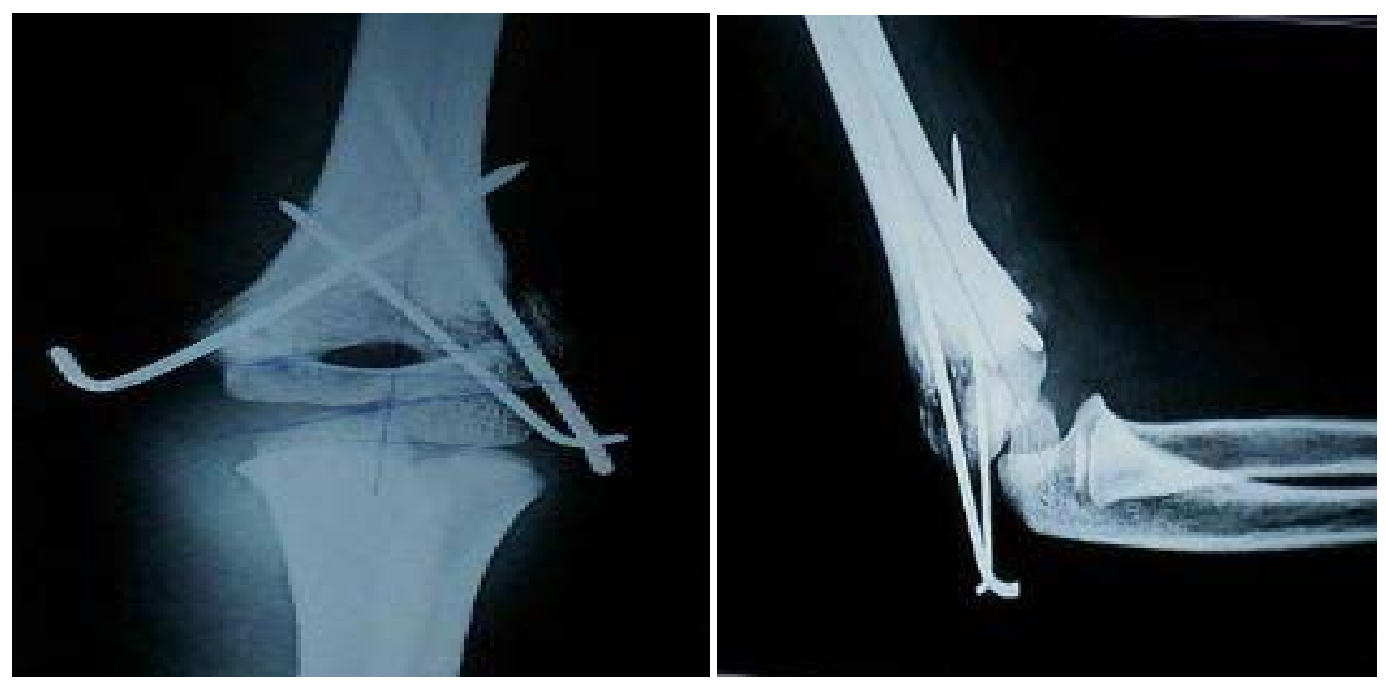

Fig 7: Shows immediate post-op radiograph with Triple pin configuration 

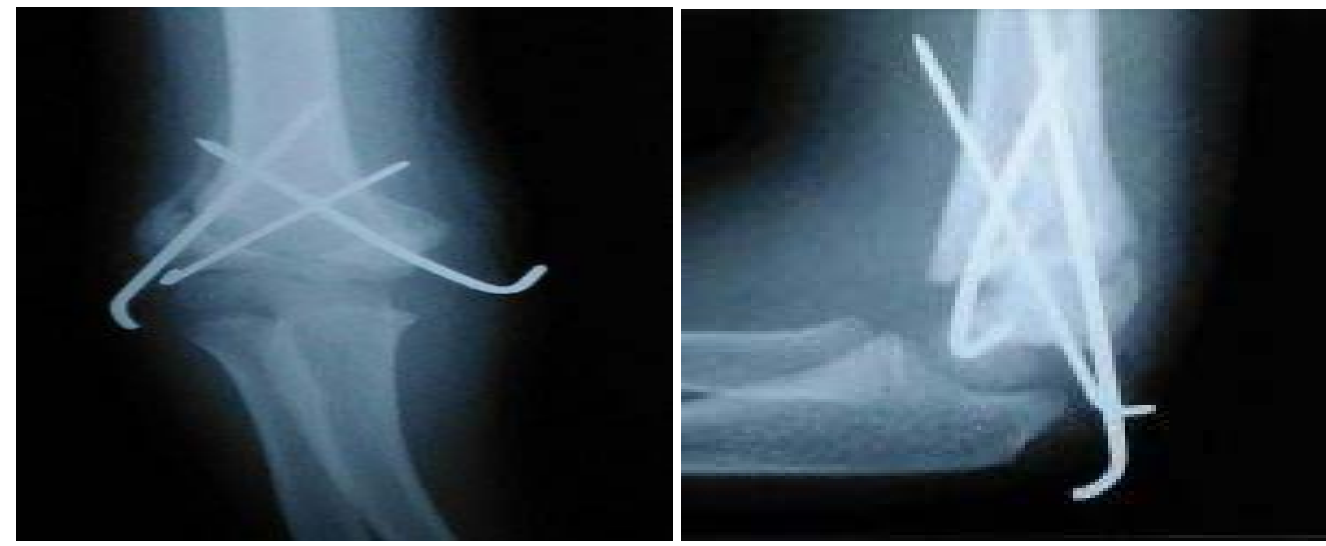

Fig 8: Shows radiograph at 4 weeks post-op
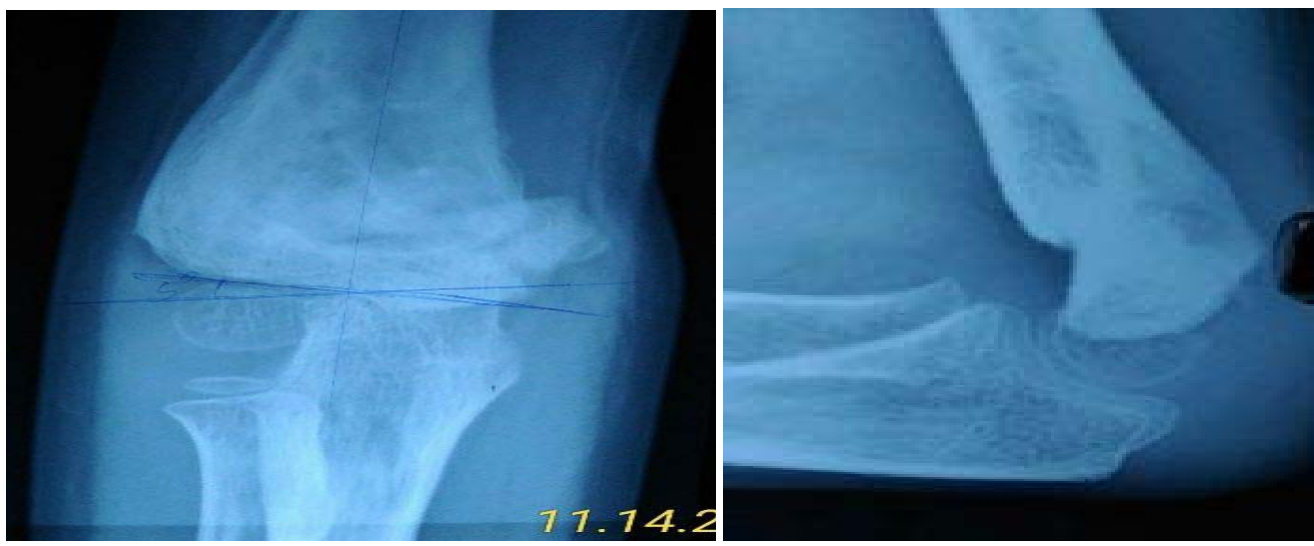

Fig 9: Shows radiograph at 6 months follow-up
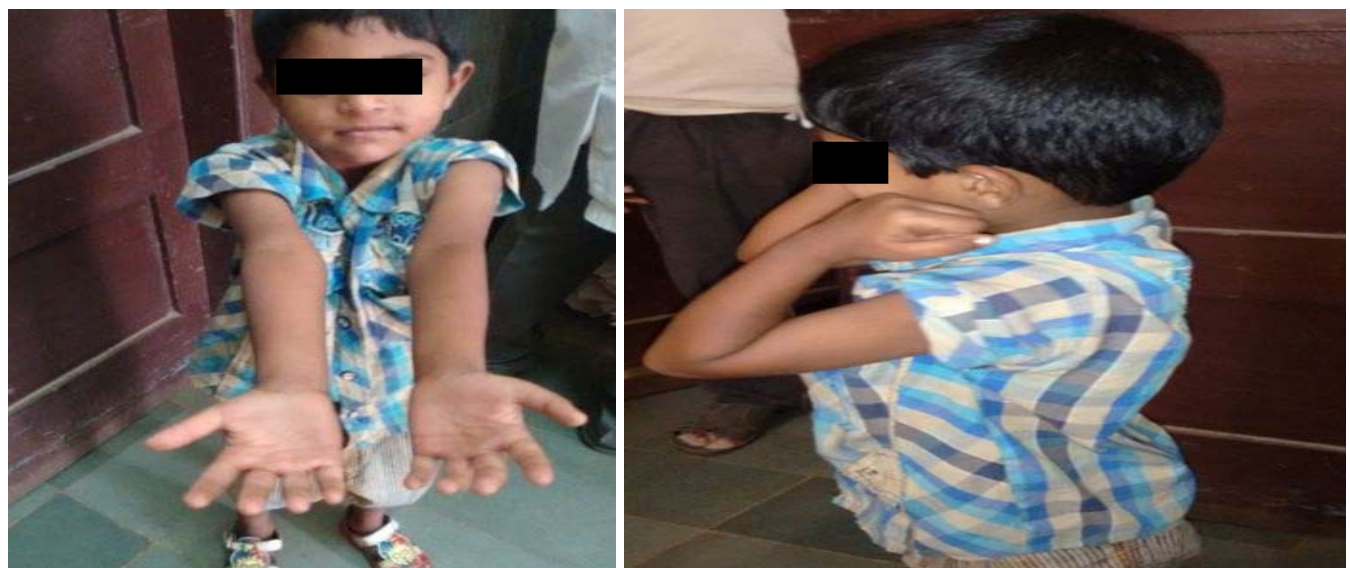

Fig 10: Shows clinical photographs at 6 months follow-up- Flexion and Extension

\section{Discussion}

The main aim of management of supracondylar fractures of humerus in children is to achieve satisfactory results in terms of functional and cosmetic point of view with minimal postoperative complications and minimal hospital stay leading to low treatment costs to patient. Closed reduction and percutaneous pinning under fluoroscopic guidance is now the accepted standard treatment for displaced supracondylar fractures of the Humerus [7]. Recent studies have shown excellent long term functional results in patients with 12-72 hours delay in presentation treated with closed reduction and percutaneous fixation. Hence patients presenting within $72 \mathrm{hrs}$ were selected for our study ${ }^{[3]}$.

Olcay et al. compared the fixation techniques used in the supracondylar fractures of the humerus anatomically and biomechanically by using the torsional strength in an adult cadaver model; and found out that the most severe resistance against the rotation strengths was obtained by fixation via a third cross K-wire from the medial in addition to the two Kwires parallel from the lateral side; while the least resistance was through the fixation with two K-wires from the lateral side; and finally the fixation with a cross $\mathrm{K}$ wire each from the medial and lateral sides wasless resistant than the fixation with three K-wires ${ }^{[8]}$.

The present study was conducted to assess the results of closed reduction and percutaneous fixation with $\mathrm{K}$ wires and comparative study between crossed pinning and triple pinning (2 lateral and 1 medial pin) in terms of clinical outcome and complications in displaced extension type supracondylar humerus fractures. 
In our study patient with average age was $8.73+1.59$ yrs. age, $88.5 \%$ patients were between 6 to $10 \mathrm{yrs}$ and $11.5 \%$ in $11-15$ yrs group. In study conducted by K. Mazda et al. ${ }^{[8]}$ mean age at presentation of 5.7 years was noted in patients, Sharma A et al. ${ }^{[9]}$ noted mean age at 6.7 yrs. in their study; Edmonds E W et $a l^{[10]}$ found average age to be 5.8 yrs. The reason behind the variation in age incidence in our study compared to previous study maybe due to incorrect details given by patients due to poor educational status of patients. All patients in age group 610 yrs $(n=23)$ had satisfactory outcome (excellent to good) compared to $10-15$ yrs age group $(n=3)$ where 2 patients had good and 1 had fair outcome suggesting better results in younger patients.

Table 1: Comparison of final clinical outcome among different age groups

\begin{tabular}{|l|l|l|l|l|}
\hline \multirow{2}{*}{$\begin{array}{l}\text { Age in } \\
\text { years }\end{array}$} & \multicolumn{2}{|l|}{ Results } & \multirow{2}{*}{ Total } \\
\cline { 2 - 5 } & Excellent & Fair & Good & \\
\hline $6-10$ & $16(100 \%)$ & $0(0 \%)$ & $7(77.8 \%)$ & $23(88.5 \%)$ \\
\hline $11-15$ & $0(0 \%)$ & $1(100 \%)$ & $2(22.2 \%)$ & $3(11.5 \%)$ \\
\hline Total & $16(100 \%)$ & $1(100 \%)$ & $9(100 \%)$ & $26(100 \%)$ \\
\hline \multicolumn{2}{|l|}{$\mathrm{P}=0.014 \%$, significant, Fisher Exact test } & \\
\hline
\end{tabular}

Edmonds E W et al. ${ }^{[10]}$ reported $45.3 \%$ patients to be males, $54.7 \%$ were females. Sharma A et al. ${ }^{[9]}$ reported $83.33 \%$ patients to be males and $16.67 \%$ females, Wilkins KE et al. ${ }^{[11]}$ reported $62.8 \%$ were males and $37.2 \%$ were females. In our study $76.9 \%$ were males and $33.1 \%$ were females, suggesting males are predisposed to these fractures possibly due to increased outdoor activities and aggressive nature in boys. In our study, $53.8 \%$ patients had fractures affecting left side while $46.2 \%$ patients had right side affection. Mazda $\mathrm{K}$ et al. ${ }^{[8]}$ reported $56 \%$ fractures on left side and $44 \%$ right side affection in 116 cases studied. Wilkins KE et al. ${ }^{[11]}$ reported $60.8 \%$ left side and $39.2 \%$ right side affection. The reason for left sided preponderance could not be explained.

Sharma A et al. ${ }^{[9]}$ reported $73.3 \%$ fractures being Gartland's type III (Posteromedial displacement-70\%, posterolateral displacement-30\%) and 26.7\% were type II. Karapinar L et al. [6] reported posterolateral displacement in $59.32 \%$ and posteromedial displacement in $40.68 \%$ of their patients. In our study 25 patients $(96.15 \%)$ out of 26 patients were type III Gartland's fracture out of which $57.7 \%$ had posteromedial displacement and $38.5 \%$ had posterolateral displacement and 1 patient $(3.85 \%)$ was type II. Type II fractures were managed by selective pinning in case closed reduction and cast immobilization fails at 5 th day follow up, hence the incidence of type II fractures were less in our study.

In our study mean injury to surgery time delay was 2.46 days. $7.7 \%$ patients were operated within 1 day, $38.5 \%$ patients within 2 days and $53.8 \%$ within 3 days. Average injury to surgery time delay noted by Skagg's et al. ${ }^{[12]}$ was 1.4 days. Dua A et al. ${ }^{[3]}$ showed excellent long term functional results with 12-72 hours delay in presentation treated with closed reduction and percutaneous fixation. In $90 \%$ patients closed reduction was successful, only $10 \%$ needed open reduction. Hence a cut off of 3 days was chosen for injury to surgery time delay, above which patients were excluded from our study. Although emergent pinning (within $12 \mathrm{hrs)} \mathrm{is} \mathrm{recommended}$ by some authors, there was a delay as our institute is a referral center with delay in presentation to the hospital.

All patients showed radiological signs of union at 4 weeks. $50 \%$ patients showed complete union at 6 weeks and $50 \%$ at 8 weeks. Mean time for union was 7 weeks. Mean loss of
Baumann angle at final follow up is 4.07 degrees. Loss of Baumann angle at final follow up and final clinical outcome as per Flynn criteria [1] had a positive association but not significant $(p=0.141)$. Reason for this association may be because Baumann angle is good predictor of carrying angle in young children before fusion of capitellar physis to lateral condylar physis as reported by Smith L ${ }^{[13]}$ in 1960. Patients with loss of Baumann angle within 5 degree compared to normal side $(n=21)$, among them $14(66.66 \%)$ patients showed excellent and 7(33.3\%) showed good outcomes. In comparison if Baumann angle is more than 5, then excellent outcome was seen in only $40 \%$ patients and $40 \%$ showed good outcome and $10 \%$ showed fair outcome.

Table 2: Comparison of Final clinical outcomes in patients and loss of Baumann angle

\begin{tabular}{|l|l|l|l|l|}
\hline $\begin{array}{l}\text { Difference of } \\
\text { Baumann } \\
\begin{array}{l}\text { Angle } \\
\text { degrees }\end{array}\end{array}$ & Results & \multirow{2}{*}{ Total } \\
\cline { 2 - 5 } $0-5$ & Excellent & Fair & Good & \\
\hline $6-10$ & $14(87.5 \%)$ & $0(0 \%)$ & $7(77.7 \%)$ & $21(80.7 \%)$ \\
\hline$>10$ & $2(12.5 \%)$ & $0(0 \%)$ & $2(22.2 \%)$ & $4(15.4 \%)$ \\
\hline Total & $0(0 \%)$ & $1(100 \%)$ & $0(0 \%)$ & $1(3.8 \%)$ \\
\hline & $\begin{array}{l}1 \\
6(100 \%)\end{array}$ & $1(100 \%)$ & $9(100 \%)$ & $26(100 \%)$ \\
\hline
\end{tabular}

In our study there 4 out of 26 patients $(15.4 \%)$ had superficial pin tract infections which were managed by appropriate antibiotics. 2 cases $(7.7 \%)$ had pin migration which were noted at 4 weeks follow-up. 1 patient $(3.8 \%)$ had varus deformity secondary to medial pin migration but had satisfactory clinical recovery at final follow-up. There were no case of iatrogenic nerve injury, vascular compromise or compartment syndrome. The difference in the incidence of complications between the crossed and triple pin configuration groups could not be given significance $(\mathrm{P}=0.378$, Not significant, Fisher Exact test). Karapinar et al. ${ }^{[6]}$ reported $3.3 \%$ incidence of iatrogenic ulnar nerve injury, pin tract infection in $6.6 \%$ and cubitus varus in $1.6 \%$ patients. Babal $\mathrm{J} \mathrm{C}$ et al. ${ }^{[14]}$ reported an overall rate of iatrogenic neuropathy of $3.9 \%$, lateral pinning neuropathy occurred at a weighted event rate of $3.4 \%$, and medial/lateral pinning nerve injury occurred at a rate of $4.1 \%$. They confirmed the risk of ulnar neurapraxia in medially pinned patients and suggest that lateral pinning may carry neurapraxic risk with respect to the median nerve. In our study all the patients $(100 \%)$ had satisfactory clinical outcome as per Flynn's criteria (excellent outcome in $61.5 \%$, good in $34.6 \%$ and fair in 3.8 patients). None of the patients had poor outcome.

Table 3: Comparison of complication rates in two pin configuration groups

\begin{tabular}{|c|c|c|c|c|c|c|}
\hline \multirow{2}{*}{ Complications } & \multicolumn{2}{|c|}{$\begin{array}{l}\text { Group C } \\
(n=13)\end{array}$} & \multicolumn{2}{|c|}{$\begin{array}{l}\text { Group T } \\
(n=13)\end{array}$} & \multicolumn{2}{|c|}{$\begin{array}{l}\text { Total } \\
(n=26)\end{array}$} \\
\hline & $\mathrm{N}_{0}$ & $\%$ & No & $\%$ & No & $\%$ \\
\hline Nil & 9 & 69.2 & 10 & 76.9 & 19 & 73.1 \\
\hline Yes & 4 & 30.7 & 3 & 23.1 & 7 & 26.9 \\
\hline - Infection & 2 & 15.38 & 2 & 15.38 & 4 & 15.4 \\
\hline - Pin Migration & 1 & 7.7 & 1 & 7.7 & 2 & 7.7 \\
\hline - Varus Collapse & 1 & 7.7 & 0 & 0.0 & 1 & 3.8 \\
\hline
\end{tabular}

$\mathrm{P}=0.378$, Not significant, Fisher Exact test 
Table 4: Comparison of Clinical outcomes between two groups.

\begin{tabular}{|l|l|l|l|l|l|l|}
\hline Final & \multicolumn{5}{l|}{ Group C } & \multicolumn{2}{l|}{ Group T } & \multicolumn{2}{l|}{ Total } \\
\cline { 2 - 7 } $\begin{array}{l}\text { Results(As } \\
\text { per Flynn } \\
\text { criteria) }\end{array}$ & No & $\%$ & No & $\%$ & No & $\%$ \\
\hline Excellent & 7 & 53.8 & 9 & 69.2 & 16 & 61.5 \\
\hline Good & 5 & 38.5 & 4 & 30.8 & 9 & 34.6 \\
\hline Fair & 1 & 7.7 & 0 & 0.0 & 1 & 3.8 \\
\hline Poor & 0 & 0.0 & 0 & 0.0 & 0 & 0.0 \\
\hline Total & 13 & 100.0 & 13 & 100.0 & 26 & 100.0 \\
\hline
\end{tabular}

The final results were evaluated using Flynn's criteria ${ }^{[1]}$ and all patients had satisfactory outcome (excellent + good + fair), none had poor outcome. Only 1 patient had 5 degrees of varus deformity and 4 cases of superficial pin tract infection successfully managed with antibiotics and 2 cases of pin migration. Most of the patients were discharged by 4th day except in superficial pin infection. After comparing our results with other similar studies we conclude that closed reduction and percutaneous $\mathrm{K}$ wire fixation is excellent modality for treating displaced supracondylar fractures of humerus in children. The Triple pinning group shows better results than Crossed pinning group but no statistical significance could be attached, reason being very small sample size in both groups. More number of cases need to be studied to attach any kind of statistical significance to the results of the comparative study

Table 5: Comparison of clinical outcomes as per Flynn criteria of our study with other related studies.

\begin{tabular}{|c|c|c|c|c|c|c|}
\hline \multirow{2}{*}{$\begin{array}{ll}\text { MODE } & \text { OF } \\
\text { TREATMENT } & \end{array}$} & \multirow[t]{2}{*}{ AUTHOR } & \multirow{2}{*}{$\begin{array}{l}\text { SAMPLE } \\
\text { SIZE }\end{array}$} & \multicolumn{4}{|c|}{ FLYNN'S CRITERIA } \\
\hline & & & EXCELLENT & GOOD & FAIR & POOR \\
\hline $\begin{array}{l}\text { Percutaneous } \mathrm{K} \text { wire } \\
\text { fixation }\end{array}$ & Present study & 26 & $16(61.5 \%)$ & $\begin{array}{l}9 \\
(34.5 \%)\end{array}$ & $1(3.8 \%)$ & $0(0.0 \%)$ \\
\hline $\begin{array}{l}\text { Percutaneous } \mathrm{K} \text { wire } \\
\text { fixation }\end{array}$ & Aronson et $\mathrm{al}^{6}$ & 20 & 18 & 2 & 0 & 0 \\
\hline $\begin{array}{l}\text { Percutaneous } \mathrm{K} \text { wire } \\
\text { fixation }\end{array}$ & Sharma $\mathrm{A}$ et $\mathrm{al}^{47}$ & 80 & $12(13.3 \%)$ & $54(60 \%)$ & $\begin{array}{l}15 \\
(16.67 \%)\end{array}$ & $\begin{array}{l}9 \\
(10 \%)\end{array}$ \\
\hline $\begin{array}{l}\text { Crossed percutaneous } \\
\mathrm{K} \text { wire fixation }\end{array}$ & Present study & 13 & $7(53.8 \%)$ & $\begin{array}{l}5 \\
(38.5 \%)\end{array}$ & $1(7.7 \%)$ & 0 \\
\hline $\begin{array}{l}\text { Triple percutaneous } \mathrm{K} \\
\text { wire fixation }\end{array}$ & Present study & 13 & $9(69.2 \%)$ & $\begin{array}{l}4 \\
(30.8 \%)\end{array}$ & 0 & 0 \\
\hline $\begin{array}{l}\text { Triple percutaneous } \mathrm{K} \\
\text { wire fixation }\end{array}$ & Karapinar et $\mathrm{al}^{43}$ & 61 & $49(80.3 \%)$ & $7(11.5 \%)$ & $2(3.3 \%)$ & $3(5 \%)$ \\
\hline
\end{tabular}

\section{Conclusion}

From our study we conclude that closed reduction and percutaneous pin fixation is a safe and excellent method for managing displaced supracondylar fractures of the humerus in children. Supracondylar fractures are common in 6-10 yrs age, more common in males and has left side predisposition. Posteromedial displacement is more common than posterolateral displacement. The clinical and cosmetic outcomes are better, fewer complications, minimal morbidity and lesser duration of hospital stay compared to other methods like closed reduction and casting, tractions and open reduction and internal fixation. This method allows elbow to be placed in more than 90 degrees of extension, thus allowing venous drainage and prevention of vascular compromise. The ideal pinning configuration is still controversial, Triple pin configuration (2 lateral and 1 medial) shows promise as a ideal pin configuration but statistical significance could not be attached to our observation due to small sample size. More cases need to be evaluated to come to statistical significance to compare crossed and triple pin configuration groups.

\section{References}

1. Piggot J, Graham HK, McCoy GF. Supracondylar fracture of humerus inchildren. Treatment by straight lateral traction. J Bone J Surg. 1986; 68B:238-242.

2. Pirone AM et al. Management of displaced extension type supracondylar fractures of humerus in children. J Bone \& Joint Surg. 1998; 70A:641-650.
3. Dua A, Eachempati KK, Malhotra R, Sharma L, Gidaganti M. Closed reduction and percutaneous pinning of displaced supracondylar fractures ofhumerus in children with delayed presentation. Chinese Journal of Traumatology. 14. 2011; 14(1):14-19.

4. Novais EN, Andrade MAP, Gomes DC. Joystick Pin in Supracondylar Humerus Fracture, J Pediatr Orthop. 2013; 33(1).

5. Gartland JJ. Management of supracondylar fractures of the humerus in children. Surg Gynecol Obstet. 1959; 109(2):145-154.

6. Karapinar L, Ozturk H, Altay T, Kose B. Closed reduction and percutaneous pinning with three Kirschner wires in children with type III displaced supracondylar fractures of the humerus. Acta Orthop Traumatol Turc. 2005; 39(1):23-29

7. Skaggs DL, Cluck MW, Mostofi A et al. Lateral-entry pin fixation in the management of supracondylar fractures in children. J Bone Joint Surg (Am). 2004; 86A(4):702-707

8. Mazda K, Boggione C, Fitoussi F, Penneçot GF. Systematic pinning of displaced extension-type supracondylar fractures of the humerus in children-a prospective study of 116 consecutive patients.J Bone Joint Surg [Br]. 2001; 83-B:888-93.

9. Sharma A, Walia JPS, Brar BS, Sethi S. Early results of displaced supracondylar fractures of humerus in children treated by closed reduction and percutaneous pinning. Indian Journal of Orthopaedics. 2015; 49(5). 
10. Edmonds EW, Roocroft JH, Mubarak SJ. Treatment of displaced paediatric supracondylar humerus fracture patterns requiring medial fixation:A reliable and safer cross-pinning technique. J Pediatr Orthop, 2012; 32:346351.

11. Wilkins KE. The operative management of supracondylar fracture in children. Ortho Clin North Am, 1990; 21(20):269-289.

12. Skaggs DL et al. Operative treatment of supracondylar fractures of the humerus in children. J Bone Joint Surg [Br]. 2001; 83-A(5);735-740

13. Smith L. Deformity following supracondylar fractures of the humerus. Am J Orthop. 1960: 42A:235-252.

14. Babal JC, Charles T, Klein MG. Nerve Injuries Associated with Pediatric Supracondylar Humeral Fractures: A Meta-analysis. J Pediatr Orthop 2010; 30:253-263. 